\title{
Guerra contra el Terror y repolitización del miedo. Alcances y efectos del terrorismo de cuño propio en las sociedades occidentales ${ }^{1}$
}

\section{War on Terror and repoliticization of the fear. Scope and effects of homegrown terrorism in Western societies}

Juan Acerbi ${ }^{2}$

\section{Resumen}

Si bien, desde la Antigüedad clásica, el miedo ha sido considerado como un factor decisivo para influir sobre el parecer de los seres humanos, su importancia cardinal para la política se formulará durante el Renacimiento y, fundamentalmente, la Modernidad. A partir de allí, el miedo será considerado el elemento esencial del orden social mientras que, por el contrario, el terror será concebido como un factor adverso a toda forma de vida civil. De esa manera, el miedo se constituyó en el vínculo privilegiado entre el poder soberano y la protección de la vida de los ciudadanos. Siglos después, esta relación sufrió cambios significativos a partir del atentado a las Torres Gemelas. Dicho atentado inició la transformación de Occidente como escenario bélico, el fin de la prerrogativa estatal a declarar la guerra y la instalación de la premisa de que toda persona, independientemente de su nacionalidad o su religión, es sospechosa de ser una amenaza

\begin{abstract}
Although, since classical antiquity, fear has been considered as a decisive factor to influence the opinion of human beings, its cardinal importance for politics will be formulated during the Renaissance and, fundamentally, Modernity. Thenceforth, fear will be considered the essential element of the social order while, on the contrary, terror will be conceived as an adverse factor to all forms of civil life. Thus, fear became the privileged link between sovereign power and the protection of the lives of the citizens. Centuries later, this relationship underwent significant changes since the attack on the Twin Towers. This attack initiated the transformation of the West as a war scenario, the end of the state prerogative to declare war and the installation of the premise that every person, regardless of nationality or religion, is suspected of being a threat to the society in which they live. Based on these considerations, this article will address the relations-
\end{abstract}

${ }^{1}$ Trabajo recibido el 02/09/2019. Aceptado el 30/11/2019.

${ }^{2}$ Universidad Nacional de Tierra del Fuego. Contacto: juanacerbi@hotmail.com 
para la sociedad que habita. A partir de dichas consideraciones, el presente artículo abordará la relación del miedo con la política y las consecuencias de la irrupción del terror como nueva variable que signa las subjetividades de las personas y las dinámicas de gobierno.

Palabras clave: Miedo; Terror; Terrorismo doméstico; Sociedad; Gobierno hip between fear and politics and the consequences of the emergence of terror as a new variable that signifies the subjectivities of people and the dynamics of government.

Keywords: Fear; Terror; Homegrown terrorism; Society; Government

¿Y quién querría ignorar que hoy ya se han formado las nubes que descargarán la tormenta del siglo XXI? Peter Sloterdijk (2010)

\section{Naturaleza y Cultura}

Aquello que la humanidad ha definido como miedo posee una extraña particularidad. Si bien el miedo es algo que pertenece al ámbito de la naturaleza humana aquello que lo provoca es producto de una cultura determinada (Delumeau, 2012; Elias, 2016; Ahmed, 2014).En cierto sentido, la historia de la humanidad podría ser considerada como un registro de las diversas técnicas e instrumentos «materiales, simbólicos y psicológicos» que los seres humanos desarrollaron para dominar sus miedos.

Sin dudas, la debilidad relativa que caracteriza, frente a otros animales, a la especie humana ha sido compensada por el desarrollo de habilidades físicas e intelectuales gracias a las que ha logrado proveerse de alimento, abrigo y seguridad frente a las inclemencias naturales, sus necesidades biológicas y la amenaza que representan otros seres vivos. A su vez, la religión y los mitos permitieron entablar una importante relación psicológica con fuerzas caprichosas que escapaban al ámbito del influjo humano. De esta manera, las fuerzas incomprensibles que gobernaban al mundo y al universo establecen un diálogo con la humanidad y por medio de designios, auspicios, epifanías y códices, el hombre no solo logró dominar parte de sus sentimientos sino que dichos instrumentos 
le permitieron ordenar el espacio social y regular su ritmo. De esta manera, la humanidad perfiló leyes y normas que, en su conjunto, le permitieron lidiar y gobernar a los hombres. Así, la política, entendida como dispositivo antropotécnico ${ }^{3}$ y como técnica de gobierno, se erigirá como la forma privilegiada para lidiar con la alteridad «humana o divina». Sin embargo, lejos de intentar conjurar el miedo, la política se alimentará de él y su correcta administración será, a la vez, uno de sus arcanos y un sensible componente de la ratio status (Foucault, 2006).

\section{El miedo perfecto}

El vínculo de la política con el miedo fue explicitado de manera temprana en la cultura occidental. Los tratados de retórica no dudaron en situar al miedo entre los sentimientos que el buen orador debía afectar con el fin de lograr el movere del auditorio y así disponerlos a su favor. En su Retórica Aristóteles no duda en acentuar la importancia de las «disposiciones favorables al miedo y [del] uso retórico de las mismas» $(1382 b, 25)$. Por otra parte, en su tratado Sobre el orador, Cicerón observa que frente a la masa «la mayor parte del discurso ha de moverse para concitar, mediante la exhortación y el recuerdo, un cambio de actitud hacia la esperanza, el miedo, el deseo o la gloria» (II 82,337). También la Biblia le ha reservado al miedo un lugar relevante si consideramos que se trata del primer sentimiento que aflora al lector del Génesis. Allí, se explica que el hombre, apenas advenido en pecador, le dice a Yahveh Dios «te oí andar por el jardín y tuve miedo, porque estoy desnudo» (Gen. 3,10).De esta manera, el miedo se convertirá en uno de los mediadores privilegiados por la tradición judeocristiana entre la humanidad y Dios. Así, mientras el cristianismo se preocupará por llegar a ser el verdadero administrador del miedo (Prodi, 2008) el judaísmo establecerá, a través de la decodificación de sus respectivos significados, una relación entre el miedo, la santidad y el nombre de Jerusalén acuñando el concepto de miedo perfecto (Breslov, 2002).

\footnotetext{
${ }^{3}$ Fabián Ludueña Romandini (2010) define los dispositivos antropotécnicos como «las técnicas mediante las cuales las comunidades de la especie humana y los individuos que las componen actúan sobre su propia naturaleza animal con el fin de guiar, expandir, modificar o domesticar su estrato biológico con vistas a la producción de aquello que, la filosofía primero, y luego las ciencias biológicas y humanas, suelen denominar 'hombre’» (p.11).
} 
Con la llegada del Renacimiento y la Modernidad el miedo se convirtió en una categoría analítica volviéndose protagonista de la política y a la vez vínculo con la racionalidad. Sin dudas, tanto Maquiavelo como Hobbes han situado al miedo como una variable propia de la política moderna (Strauss, 1959), la cual forma parte de la naturaleza humana debiendo, por lo tanto, ser apropiadamente considerada y administrada por parte de aquel que detente el poder político. Maquiavelo no dudará en sopesar las ventajas que ofrece el ser amado o temido y, ante la dificultad de conciliar ambos sentimientos, se inclinará por el temor. El florentino entendía que el vínculo del amor suele ser roto por la mezquindad de los hombres y por los vaivenes que provoca la Fortuna mientras que el temor es más firme y estable debido a que «lo mantiene un miedo al castigo que nunca te abandona» (2014, p. 119). Pero será Hobbes quien vuelva al miedo no solo una variable del poder y una técnica de gobierno sino que lo concebirá como el principio constitutivo del orden social y político.

Mientras que para los griegos la polis nacía del carácter naturalmente social del hombre y, fundamentalmente, del sistema de necesidades que se derivaban de su existencia, para los romanos la societas era la expresión de una racionalidad que caracterizaba al hombre como ser social a la vez que lo vinculaba con la divinidad más allá de cualquier necesidad que pudiera padecer. ${ }^{4}$ En términos sociales y políticos, en la Antigüedad clásica el miedo no desempeñaba ninguna función constitutiva del ser y del espacio social y se encontraba vinculado al ámbito del desempeño personal en relación a las virtudes cardinales o cívicas. Será el pensamiento teológico del cristianismo primitivo el que establecerá una relación entre el carácter de las personas y su comunidad cuando se entienda que la comunidad cristiana se relaciona con Dios a través de sentimientos como el amor y el miedo (Iogna-Prat, 2010; Berman, 1983). Sin embargo, es con el pensamiento hobbesiano que el miedo se transforma en la quintaesencia del Estado, la sociedad y la política. Es debido a este sentimiento que los hombres tienen por sus semejantes que deci-

\footnotetext{
${ }^{4}$ Bastará recordar, por una parte, la discusión en torno a la ciudad de cerdos que transcurre en República (II 372a « 374e)de Platón o el primer libro de Política de Aristóteles para comprender la impronta que posee el sistema de necesidades para pensar la polis. Cicerón, en cambio, establecerá una relación entre la condición social y política del hombre con una decisión racional (Rep. I 25,39) que encuentra su fundamento último en la divinidad. Al respecto, pueden consultarse, además de su ya citado Sobre la república, los dos primeros libros de su tratado Sobre la naturaleza de los dioses.
} 
den abandonar ese estado en el que, si bien gozan de una libertad absoluta, la vida se encuentra bajo amenaza permanente. Así, movilizados por el miedo a perder sus vidas, los hombres conforman un cuerpo social sometiendo sus bríos a las leyes y, especialmente, a la voluntad del soberano (Hobbes, 1982).

Sin embargo, no hay que pasar por alto el hecho de que si bien Hobbes apela al miedo como el principal factor anímico que posibilita la constitución de la sociedad civil y el Estado, su distinción respecto al terror resulta de capital importancia. El término latino que Hobbes utiliza para referirse al sentimiento que lleva a los hombres a salir del estado de naturaleza y constituirse en sujetos políticos es metus ${ }^{5}$ y las implicancias del mismo coincidirán con la distinción que siglos después se establecerá entre miedo (metus) y terror (pavor). Si, como se ha sostenido, la distinción entre miedo y terror radica en la presencia «o no» del objeto que provoca dichos sentimientos (Freud, 1992), podemos aseverar que en la tradición política iniciada en la Modernidad, son los otros seres humanos los que encarnan y representan, para cada individuo en particular, la fuente de temor gracias a la cual es posible eludir el terror y convertir la angustia en acción. Esta es la lectura que ha llevado a Roberto Esposito (2007) a afirmar que el miedo posee una carga constructiva ya que «no determina únicamente fuga y aislamiento, sino también relación y unión» debido a que el miedo «no se limita a bloquear e inmovilizar, sino que, por el contrario, impulsa a reflexionar y a neutralizar el peligro: no está del lado de lo irracional, sino del lado de la razón» (p. 57 ). De esta manera, Esposito explicita la relación que la filosofía hobbesiana concibió entre miedo, política y racionalidad. Si bien dicha relación no ha sido en sí misma cuestionada, la misma debería ser reconsiderada a la luz de las nuevas experiencias que se han vivenciado en Occidente desde los inicios del presente siglo.

\section{El desplazamiento del miedo}

La distinción entre miedo, angustia y terror se establece en función de la presencia de la fuente de la cual emana el peligro y del grado

${ }^{5}$ De la edición de 1782 del De Cive leemos, por ejemplo, Canfa metus mutuiconfiftit, partim in naturali hominume qualitate (I»III), major metus violan dae fidei(II»XX), Denique extra civitatem, imperium affedtuum, belum, metus, paupertas... (X»I). Ver también, en la misma obra, XIII»VII, XIII»XVI, XVI»I, XVII»XXV. 
de conocimiento previo que tengamos de la amenaza que la misma representa. Mientras que la angustia se produce gracias a «un peligro desconocido», Freud (1992) puntualiza que «el miedo requiere de un objeto determinado en presencia del cual uno lo siente; en cambio, se llama terror al estado en que se cae cuando se corre un peligro sin estar preparado: destaca el factor sorpresa» (p. 12).Por lo tanto, si consideramos las característica que permiten definir y delimitar al miedo, podemos afirmar que en las bases de la política y del Estado Moderno la fuente de la amenaza que permite movilizar los sentimientos hacia el miedo «evitando la angustia y el terror» son los otros seres humanos que cohabitan junto a nosotros. Es decir, son esos otros que conforman la humanidad los que representan una amenaza para nuestra vida. De esta manera, la amenaza que representa cada hombre para el resto de los de su especie es lo que ha posibilitado que los seres humanos se vuelvan, a través de la política y las técnicas de gobierno, sujetos políticos. De esta manera, es posible afirmar que los seres humanos pudieron encontrarse y convivir bajo una misma norma cuando fueron capaces de erradicar parte de su propia humanidad gracias a lo cual les fue posible constituirse en sujetos de un derecho y habitantes de una ciudad. ${ }^{6}$ Según esta tradición, el miedo se convierte en el único sentimiento capaz de contener los impulsos y las ambiciones humanas al punto de volverlo un animal doméstico y esta es la razón por la cual el miedo no puede «o no debería» ser erradicado de la política.

Mientras que la eliminación de toda forma de temor supondría la anomia social y la extinción del poder soberano, la exacerbación del miedo provocaría que la masa dé por finalizado el pacto que lo ata al soberano y busque garantizar su seguridad por sus propios medios. En este sentido, es posible afirmar que el poder político solo puede preservarse en la medida en la que el miedo es «parafraseando a Platón» administrado como un fármaco, en su justa medida, por aquellos que gobiernan. En términos de una economía política del miedo, los niveles de tolerancia al mismo limitan con la capacidad y las herramientas que poseen las personas para seguir comportándose, al menos en su mayoría, como seres racionales. Que el comportamiento de la población se mantenga dentro de los márgenes de la previsibilidad es lo que permite mantener la gubernamentalidad dentro del marco jurídico legal del Estado de de-

\footnotetext{
${ }^{6} \mathrm{Al}$ respecto, resulta de interés la relación que establece Agamben (2019) entre la figura del soberano y aquellos que habitan la ciudad.
} 
recho. En definitiva, la política, lejos de venir a conjurar el miedo, debe encargarse de producirlo, mantenerlo latente y orientarlo hacia un objeto concreto de manera tal que los ánimos de la población no desborden los límites institucionales. Sin embargo, la situación humanitaria y los hechos que, como los atentados perpetrados el 11 de septiembre de 2001 en Nueva York, marcaron el inicio del presente siglo debería hacernos reconsiderar la relación que la Modernidad le ha asignado al binomio miedo»política.

Es probable que debamos considerar la enunciación realizada por Walter Benjamin (1989) sobre el hecho de que «la regla es el estado de excepción en que vivimos» (p. 182) como una de las primeras denuncias sobre un cambio de paradigma en torno al poder soberano. Sin embargo, los años transcurridos desde aquel entonces evidenciaron la influencia que ejercía un poder de esas características sobre las formas de producción de subjetividad y de sociabilidad. Mientras que el concepto de estado de excepción ha animado algunos de los debates más intensos en el ámbito del derecho (Schmitt, 2009 y 2013; Kelsen, 1965 y 1982), la filosofía política se vio obligada a revisitar las instituciones jurídicas, políticas y religiosas «tanto clásicas y medievales como modernas» en pos de comprender los mecanismos que ofician detrás del poder soberano y sus implicancias actuales (Acerbi, 2019; Agamben, 2005 y 2017; Ludueña Romandini, 2010).Como ha sido señalado, una de las consecuencias inminentes del estado de excepción es la producción de nuda vida, es decir, la degradación de la vida humana a su estrato biológico ${ }^{7}$ reduciendo de esa manera las particularidades propias de cada persona a las de un mero ser vivo. Pero dicho proceso no alcanza exclusivamente al status jurídico del individuo sino que, como bien ha señalado Hannah Arendt (2017), se logra también afectar la propia subjetividad de la persona al punto de llegar a afirmarse que es posible que la persona sea abandonada por su propio yo. ${ }^{8}$ Por lo tanto, deben extenderse los límites

${ }^{7}$ En este punto resulta capital la distinción griega entre las dos formas que podía adoptar la vida. Una forma superior (bios) caracterizada, fundamentalmente, por el vínculo que los hombres establecen entre sí a través del logos y la vida en comunidad que se expresa en la polis. Por otra parte, existe una forma de vida inferior (zoe) que es la que comparten los animales $y$, en general, los seres que viven por fuera de una comunidad organizada políticamente. Esta distinción es el punto desde el que parte el desarrollo teórico de Agamben (2005) sobre la figura del Homo sacer. Algunos contrapuntos a dicha perspectiva, centrada en la figura de Aristóteles, son señalados en el ya citado trabajo de Ludueña Romandini (2010). ${ }^{8}$ Hecho de capital importancia para comprender la forma en la que los totalitarismos 
dentro de los que se piensa la figura del homo sacer ya que, al menos en su declinación contemporánea, implica también la exposición de un ser humano no solo en su dimensión jurídica sino también en su dimensión moral. Los numerosos análisis que vinculan la producción de nuda vida con la indiferencia con la que se naturalizan las condiciones de violencia que atraviesa diariamente buena parte de la población mundial no hacen más que enfatizar lo próximos que nos encontramos a aceptar «por acción u omisión» la muerte de cualquier ser humano. En este sentido debe ser leído en toda su intensidad aquel llamado de atención que Judith Butler (2004) realiza sobre la necesidad de reconsiderar los límites que circunscriben aquello que llamamos ser»humano y, en consecuencia, repensar el sentido «O el sinsentido» que tiene en la actualidad apelar a tratados internacionales u organismos de Derechos Humanos cuando los límites sobre qué es lo humano y lo humanitario es lo que está en cuestión.

En una época en la que el término «bombardeo humanitario»se ha instalado en el léxico de políticos y comunicadores, la tarea de tener que repensar los límites que permiten diferenciar aquellas vidas que son dignas de ser protegidas de aquellas que merecen ser expuestas resulta apremiante. Pero dicha tarea no puede soslayar el hecho de que Occidente ha incorporado, desde inicios del Siglo XXI, en detrimento del miedo, el terror como variable política pero también como cifra que impone su marca a las relaciones sociales, jurídicas y económicas.

\section{El miedo difuso y la lógica del terror}

Herfried Münkler ha señalado que el siglo XXI se ha iniciado con una serie de modificaciones que alteraron las características clásicas de la guerra «y del lugar que el Estado tenía en relación a la misma» dando lugar a muevas guerras. Entre las características que Münkler (2005) re-

\footnotetext{
lograban destruir la personalidad de los detenidos en los campos de concentración. Arendt define ese estado «en el que el yo abandona al yo» como soledad. La soledad, a partir de la conceptualización formulada por Arendt, se define como un estado en el que la persona ya no puede relacionarse consigo mismo ni, por supuesto, con otros. El paradigma de dicha figura es la de los así denominados musulmanes. Sobre la figura del musulmán en el contexto de los campos de concentración resulta insoslayable la obra de Primo Levi mientras que Agamben (2018) realiza un análisis del musulmán en el contexto de su genealogía sobre la figura del homo sacer.
} 
salta como novedosas se encuentran «la desestatalización o privatización de la violencia bélica» y «la asimetría de la violencia bélica, es decir el hecho de que, por regla general, no luchan entre sí contendientes comparables» (p. 4). Luego agrega una tercera característica que se coliga con las anteriores ya que remarca el hecho de que «los ejércitos regulares han perdido el control del acontecer bélico» a la vez que el mismo «ha caído en manos de actores de violencia a los que les ajena la guerra como disputa entre fuerzas análogas» (p. 4). Independientemente de la lucidez de las observaciones que realiza Münkler, para comprender la forma en la que las nuevas guerras afectan a las poblaciones que las padecen, será necesario abordar la relación que el pensamiento político moderno fijó entre política, seguridad y guerra. De dicho análisis surgirán algunas pautas sobre la forma en la que el miedo y el terror configuran el escenario político y social actual.

Si la concepción del Estado moderno encontraba en el miedo el sustrato que posibilitaba su existencia y la de la sociedad civil, el concepto de soberanía no será menos importante cuando el objetivo sea ordenar y mantener el orden y la paz interna. Si uno de los atributos fundamentales del soberano es mantener la seguridad de los súbditos, el otro, de igual relevancia e íntimamente ligado al anterior, es el de proclamar la guerra (Hobbes, 1982).No caben dudas que, en años recientes, ambos atributos le han sido fuertemente cuestionados a los Estados especialmente en los casos de crímenes de odio cometidos por sus propios ciudadanos. $^{9}$ La reacción ha sido la de extremar las condiciones de la

\footnotetext{
${ }^{9}$ A diferencia de lo que suelen sugerir las noticias, los crímenes de odio o vinculados a una ideología de extrema derecha producen, año a año, considerablemente más muertes que los atentados producidos por terroristas provenientes de Medio Oriente (Koehler, 2019). Masacres como la de la isla de Utøya (Noruega) o la de Christchurch (Nueva Zelanda) evidencian, por una parte, lo poco preparados que están los Estados para detectar este tipo de actividades cuando quien actúa lo hace como Lobo solitario (Bjørgo 2013; Simon 2013)y, por otra parte, cuando el atacante es hijo de la propia sociedad contra la que atenta. Sobre la figura de Anders Behring Breivik y la masacre de Utøya puede consultarse Berntzen y Sandberg (2014) y Hemmingby y Bjørgo (2016). Respecto a los hechos ocurridos a mediados de marzo de 2019 en Nueva Zelanda, resulta de interés la convocatoria, formulada por la Primera Ministra de Nueva Zelanda, Jacinda Ardern, conocida como Christchurch Call to Action Summit. La reunión, realizada en París bajo el auspicio del Presidente Emmanuel Macron, y cuyo eje principal era tratar el rol de las redes sociales en actos terroristas será, con toda seguridad, materia convocante para los especialistas de diversas disciplinas debido al nivel de información que detentan las Big Tech en comparación con los Estados y al rol activo que juega internet a la hora de planificar los atentados y difundir propaganda.
} 
vigilancia a costa de vulnerar los límites del Estado de bienestar mientras que la guerra es algo que los gobernantes solo declaran tardíamente como reacción a un hecho de violencia ya consumado. De esta manera, nos encontramos frente a dos factores que resultan decisivos para comprender la situación a la que nos enfrentamos en la actualidad. La pérdida de la atribución soberana a declarar la guerra no es solo un aspecto que deba ser considerado de manera aislada sino que debe asociarse al hecho de que las guerras son declaradas no por un Otro, externo y ajeno a nuestra comunidad, sino por un otro que es uno más de nosotros. Este fenómeno es de particular importancia y debería agregarse como una de las características más sensibles de las nuevas guerras. El hecho de que la sospecha no recaiga sobre una alteridad identitaria hace que la desconfianza se extienda hacia el interior de nuestra propia comunidad impidiendo cualquier tipo de contacto legítimo, humanitario, con el otro. De esta manera, cualquiera que ingrese a un edificio público o deposite una pequeña maleta en el asiento del subterráneo despierta sospechase inquieta a aquellos que lo circundan. En términos esquemáticos, lo que ha ocurrido es que se ha producido un desplazamiento no solo del campo de batalla sino que se ha difuminado el estereotipo de aquel que representaba la amenaza de guerra y de muerte. Si bien no hay dudas de la importancia que tiene que el campo de batalla se haya trasladado de Oriente Medio a Occidente, el hecho de que la figura del terrorista haya pasado de ser la del estereotipo del hombre afgano o iraní a la de cualquiera de nuestros vecinos no es menor. De hecho, es probable que solo podamos comprender los efectos más profundos que tiene sobre las poblaciones occidentales la importación del escenario bélico a partir de las implicancias que tiene el que la identidad del terrorista se funda con la del resto de los ciudadanos que habitan nuestras ciudades.

En este contexto, no es casualidad que una figura del derecho romano clásico, que daba cuenta del peligro que significaba lidiar con un enemigo interno, ya que el estado que provocaba «el tumultus» era peor que el de una guerra (Lintott, 2008), haya llamado la atención de juristas y filósofos. El hostis se caracterizaba, precisamente, por ser aquel que, siendo un romano más, se volvía un enemigo que deseaba y perseguía el fin de la sociedad romana. Al tomar conocimiento de que existía una amenaza interna de tal magnitud, los romanos decretaban el iustitium, es decir, la suspensión de la ley y las garantías civiles. El paralelo puede extenderse, con sus debidas precauciones, hasta la situación que enfrentamos actualmente a nivel global. En este sentido, podría estable- 
cerse una relación entre la figura y los efectos que el hostis provocaba en la sociedad romana con la influencia que actualmente ejerce la figura del terrorista de cuño propio. En consecuencia, no deberíamos esperar que una sociedad que se encuentra en una situación con estas particularidades se caracterice por mantener vínculos interpersonales mediados por la amabilidad y la empatía sino por un sentimiento de desconfianza propia del sobreviviente que percibe en cada uno de sus semejantes a un enemigo (Canetti, 2013).Por otra parte, tampoco es factible que la política, tal como la hemos concebido desde la Modernidad, sea la que ejerza su imperio y es por ello que el estado de excepción no tiene posibilidad de ser revocado lo cual implica sepultar cualquier posibilidad de reconducir la vida institucional en términos de un Estado de derecho.

El hecho de que el miedo no fuera algo a erradicar, sino a administrar, formaba parte de los arcanos de la política por más de una razón. Mientras que el miedo es lo que posibilita el orden social a la vez que constituye y legitima el poder soberano en manos del Estado, la producción del mismo tiene que mostrarse externo y antagónica al poder político aunque éste se alimente de aquel. Es por ello que la administración del miedo debía realizarse por vías subrepticias cuidando que el mismo no desaparezca ni supere los límites de lo tolerable ya que, en ambos casos, nuestra tradición señala que la política se volverá mera violencia y la sociedad retornará a su fase de total anomia. Si, como magistralmente ha señalado Jeanne Marie Gagnebin (2005), «la definición de las causas del mal, de los portadores del peligro, tiene que ser simple para ser eficiente» (p. 13), lo disruptiva que resulta, en este sentido, la incorporación de la figura del terrorista como variable del trato interpersonal y de la vida cotidiana evidencia la crisis social, identitaria y política que sufren las instituciones civiles y gubernamentales.

En relación a estos fenómenos, el hecho de que el centro de la atención sea comúnmente puesto en el hemisferio norte no debe hacernos perder de vista que las subjetividades, los discursos y las políticas que circulan en torno al fenómeno del terrorismo trascienden los límites geográficos. En países como Argentina puede comprobarse que tanto el léxico como ciertas medidas adoptadas en materia de seguridad y de políticas públicas tienden a centrarse en torno al fenómeno del terrorismo independientemente de si existen causas objetivas para implementarlas. Por otra parte, no solo la cuestión debe ser tratada a nivel jurídico o político sino también a nivel social máxime cuando se instalan discursos y estereotipos que operan como catalizadores de prejuicios sociales, 
económicos y culturales que pueden favorecer acciones violentas o crímenes de odio. El hecho de que la Corte Suprema de Justicia de la República Argentina se haya pronunciado sobre la forma en la que un individuo va perdiendo «en el espejo de parte de [la] sociedad, sus caracteres de persona humana, hasta el punto de serle desconocidos irreparablemente» (CSJNA 318:1894) debe ser considerado a la luz de un fenómeno de carácter global. La desaparición del rosto del otro es precisamente el rasgo característico de una época que percibe que cada integrante de la humanidad es una amenaza para su integridad. A su vez, los poderes gubernamentales, reconociendo que cada individualidad debe ser considerada una amenaza, implementan sistemas de control y vigilancia cada vez más masivos extendiendo los límites de la excepcionalidad. En otros términos, diremos que cuando no hay posibilidad de distinguir la identidad del ciudadano que se debe proteger de aquel que lo amenaza no hay posibilidad de que el universo jurídico responda dentro del ámbito de la normalidad. Si, como rezaba el adagio latino, «la necesidad no tiene ley», la razón de Estado impone el imperio de la excepción mientras que la gravedad de la situación elimina cualquier posibilidad de lidiar con el gobierno político de lo humano al excluir el miedo como causa primaria y lógica del poder soberano.

En un mundo sin zonas seguras y sin rostros en los que reconocerse la única respuesta posible seguirá siendo aquella que priorice la eliminación del otro por sobre cualquier noción de comunidad o bienestar general. Paradójico será, sin dudas, reclamar el regreso del miedo como factor político y de ordenamiento social. Este será uno de los principales desafíos de la humanidad para lo que resta del siglo, recuperar su relación con el miedo y procurar erradicar el terror como principio rector de las relaciones humanas.

\section{A modo de conclusión}

Desde la Antigüedad la historia de los arcanos de la política revelan al miedo en un lugar visible pero secundario a la hora de dar cuentas del carácter político del hombre y del origen de la sociedad. Con el Renacimiento y la llegada de la Modernidad el miedo se constituyó en una mercancía que debía ser administrada en pos de mantener el equilibrio que sostenía la cohesión social y la primacía de la política como forma de gobierno. El léxico hobbesiano anticipó lo que formalizaría Freud siglos 
después y de esa manera se sentaron las bases que permitieron distinguir con claridad las causas y las diferencias existentes entre miedo y terror.

En términos políticos, el miedo se ha definido como una de las fuentes primarias de toda acción racional. En otras palabras, el miedo es lo que lleva a los seres humanos a volverse sujetos, a constituirse en integrantes de una sociedad y a fijar un ámbito de derecho común y libertad. Sin embargo, y a la luz de los hechos que se siguieron en Occidente a partir del atentado del 11 de septiembre, sostuvimos que el miedo ha sido erradicado de las variables que animan la razón de Estado y que, en su lugar, ha sido el terror el que ha cooptado tanto la política como la subjetividad de los habitantes de las urbes de nuestro planeta.

El siglo XXI se inició con la inversión de los escenarios bélicos y las cadenas de televisión, que solían transmitían imágenes que llegaban de miles de kilómetros, pasaron a transmitir las mismas imágenes desoladoras pero ahora desde las calles de París, Madrid o Berlín. Pero esa inversión fue, poco a poco, siendo acompañada por otra que resultaría mucho más angustiante y cuyos resultados estamos apenas comenzando a vislumbrar. Mientras que el escenario de la guerra se trasladó a Occidente, el enemigo no fue importado sino que pasó a surgir del ámbito de nuestras propias sociedades, de las casas de nuestros vecinos y familiares. Las personas que, a pesar de tener una vida normal devienen en responsables de un atentado ha eliminado toda posibilidad de que sea el miedo el que guíe nuestras acciones. El extrañamiento (Unheimlich) es, precisamente, aquello que se produce cuando lo familiar deviene en algo extraño y el rostro del otro se desdibuja hasta coincidir con la de otro mientras que un simple objeto o herramienta doméstica «un cuchillo de cocina o un martillo» desata el pánico en el transporte público por el simple hecho de que nada de lo familiar garantiza su verdadera pertenencia a la comunidad.

Considerando todo lo expuesto hasta aquí, tal vez se deba tomar aquella proclama de llevar a cabo una Guerra contra el Terror declinándola en un sentido diferente al que originariamente le dio el entonces presidente de los Estados Unidos. Llevar a cabo una Guerra contra el Terror debería significar, considerando nuestra propia tradición política, realizar acciones tendientes a erradicar la impronta hegemónica del terror del ámbito urbano para restituir un espacio en el que la economía del miedo vuelva a ser uno de los sustratos que animan y sostienen las relaciones sociales, jurídicas, políticas y económicas. La tarea no puede 
comenzar sin una política que propicie la recuperación del espacio público como lugar privilegiado del trato con las alteridades. La distinción entre la simple alteridad y la alteridad radical debería también ser repolitizada evitando el discurso «que nada tiene de naive» de que es posible entablar vínculos sociales y políticos «seguros» y en base al consenso. Repolitizar el miedo implica aceptar que el encuentro con los otros se produce a partir de los desacuerdos, las desconfianzas y los temores. Esta será una de las tareas que deberá afrontar la política que se cargue con la tarea de devolverle a la humanidad algo de su gobierno.

\section{Referencias bibliográficas}

Acerbi, J. (2019). Metapolitica. Enemigo público, poder y muerte civil en la tradición republicana. Buenos Aires, Argentina: Miño y Dávila.

Agamben, G. (2005). Homo sacer. Ilpoteresovrano e la muda vita. Torino, Italia: Einaudi.

Agamben, G. (2017). Stato di eccezione. Homo sacer, II, 1. Torino,Italia: Bollati Boringhieri.

Agamben, G. (2018). Quel che resta di Auschwitz. L'archivio e iltestimone. Torino, Italia: Bollati Boringhieri.

Agamben, G. (2019). Stasis. La guerra civile come paradigma politico. Homo sacer, II,2. Torino: Bollati Boringhieri.

Ahmed, S. (2014) The Cultural Politics of Emotions. Edimburgo, Escocia: Edinburgh University Press.

Arendt, H. (2017). The Origins of Totalitarism. Londres, Inglaterra: Penguin Books.

Aristóteles. (1999). Retórica. Madrid, España: Gredos.

Benjamin, W. (1989). Tesis de filosofía de la historia en Discursos interrumpidos I. Madrid, España: Taurus.

Berman, H. (1983). Law and Revolution. The Formation of Western Legal Tradition. Massachusetts, Estados Unidos: Harvard University Press.

Berntzen, L. E. y Sandberg, S. (2014). «The Collective Nature of Lone Wolf Terrorism: Anders Behring Breivik and the Anti-Islamic Social Movement». Terrorism and Political Violence (Octubre 2014). DOI: 10.1080/09546553.2013.767245 
Biblia de Jerusalén. (1967). Revisada y aumentada. Bilbao, España: Edición Desclee de Brower.

Bjørgo, T. (2013). Strategies for Preventing Terrorism. Londres, Inglaterra: Palgrave.

Breslov, Rabí Naimán de (2002). Anatomy of the Soul. Jerusalen, Israel/ Nueva York, Estados Unidos: Breslov Research Institute .

Butler, J. (2004). Precarious Life. The Powers of Mourning and Violence. Londres, Inglaterra/Nueva York, Estados Unidos: Verso.

Canetti, E. (2013). Masa y poder. Barcelona, España: Alianza.

Cicerón, M.T. (2000). On the Republic. On the Laws. Massachusetts, Estados Unidos: Harvard University Press. Edición Bilingüe (Latín-Inglés).

Cicerón, M.T. (1999). Sobve la naturaleza de los dioses. Madrid, España: Gredos.

Corte Suprema de Justicia de la Nación Argentina (CSJNA). Fallo 318:1894 (D.346 XXIV).

Delumeau, J. (2012). El miedo en Occidente. (Siglos XIV-XVIII). Una ciudad sitiada. Madrid, España: Taurus.

Elias, N. (2016). El proceso de civilización. Investigaciones sociogenéticas y psicogenéticas. México, México:Fondo de Cultura Económica.

Esposito, R. (2007). Communitas. Origen y destino de la comunidad. Buenos Aires, Argentina: Amorrortu.

Foucault, M. (2006). Seguridad, territorio, población. Buenos Aires, Argentina: Fondo de Cultura Económica.

Freud, S. (1992). Obras completas XVIII. Más allá del principio del placer. Psicología de masas y análisis del yo y otras obras (1920-1922). Buenos Aires, Argentina: Amorrortu.

Gagnebin, J. M. (2005). «Después de Auschwitz». Boletín de Estética (3). Programa de Estudios en Filosofía del Arte, Centro de Investigaciones Filosóficas.

Hemmingby, C. y Bjørgo, T. (2016). The Dynamics of a Terrorist Targeting Process. Anders B. Breivik and the 22 JulyAttacks in Norway. Londres, Inglaterra: Palgrave.

Hobbes, T. (1782). Elementa Philosophica De Cive. Amsterdam.

Hobbes, T. (1982). Leviatán. O la materia, forma y poder de una repúbli- 
ca eclesiástica y civil. México, México: Fondo de Cultura Económica.

Iogna-Prat, D. (2010). Iglesia y sociedad en la Edad Media. México, México: UNAM.

Kelsen, H. (1965). Teoría general del Estado. México, México: UNAM.

Kelsen, H. (1982). Teoría pura del derecho. Buenos Aires, Argentina: EUDEBA.

Koehler, D. (2019). «Violence and Terrorism from the Far-Right: Policy Options to Counter an Elusive Threat». ICCT Policy Brief. DOI: 10.19165/2019.2.02

Lintott, A. (2008). Cicero as Evidence. A Historian's Companion. Oxford, Inglaterra: Oxford University Press.

Ludueña Romandini, F. (2010). La commnidad de los espectros. Antropotecnia I. Buenos Aires, Argentina: Miño y Dávila.

Machiavello, N. (2014). Il Principe. Torino, Italia: Einaudi.

Münkler, H. (2005). Viejas y muevas guerras. Asimetría y privatización de la violencia. Madrid, España: Siglo XXI.

Platón. (1988). Diálogos IV. República. Madrid, España: Gredos.

Prodi, P. (2008). Una historia de la justicia. De la pluralidad de fueros al dualismo moderno entre conciencia y derecho. Buenos Aires, Argentina: Katz.

Simon, J. D. (2013). Lone wolfterrorism: Understanding the growing threat. Nueva York, Estados Unidos: Prometheus Books.

Sloterdijk, P. (2010). Ira y tiempo. Madrid, España: Siruela.

Strauss, L. (1959). What is political philosophy? And other studies. Chicago, Estados Unidos: The Chicago University Press. 